\title{
Experiencia laboral durante los estudios y desajuste educativo en el primer empleo en los graduados universitarios españoles
}

\author{
Cecilia Albert \\ Universidad de Alcalá \\ María A. Davia \\ Nuria Legazpe \\ Universidad de Castilla-La Mancha
}

\begin{abstract}
Resumen
En este trabajo estudiamos el impacto que tienen en el desajuste educativo en el primer empleo de los jóvenes graduados en España diferentes tipos de experiencia laboral durante los estudios: la adquirida mediante trabajos remunerados y la resultante de prácticas externas. Identificamos tres tipos de desajuste entre la cualificación y el primer empleo de los universitarios (sobreeducación, en conocimientos o habilidades y por rama de estudios). Nuestra conclusión fundamental es que la experiencia laboral (remunerada o vía prácticas curriculares) durante los estudios solo reduce las posibilidades de desajuste en el primer empleo si está relacionada con los estudios y no es esporádica.
\end{abstract}

Palabras clave: desajuste educativo, experiencia laboral, prácticas externas, graduados universitarios.

Clasificación JEL: J24, I23, I26.

\section{Abstract}

In this paper we study the impact of work experience while in university on graduates' first educational mismatch in Spain. We analyse two types of labour market experience, namely, paid work and placement positions. We identify three types of mismatch in graduates' first jobs: overeducation, skills mismatch and mismatch in the field of studies. Our main conclusion is that labour market experience (either via paid employment or with curricular placements) during undergraduate education only reduces mismatch risks in the first graduates' jobs when it is related with their studies and not sporadic.

Keywords: education mismatch, work experience, university placements, university graduates.

JEL classification: J24, I23, I26.

\section{Introducción}

El desajuste de la cualificación del trabajador con los requerimientos de su empleo es un indicador de subempleo de los recién graduados y de la falta de sintonía entre el sistema universitario y el mercado de trabajo. Para las instituciones de 
educación superior el desajuste de sus graduados con los requerimientos de su primer empleo es un resultado no deseado de su actividad y suele utilizarse como una medida de la calidad de sus servicios (Lindberg, 2007; Dacre Pool y Sewell, 2007). Por tanto, que estos jóvenes inicien la carrera profesional con un empleo adecuado a su cualificación es una de las mayores preocupaciones de las instituciones de educación superior, pero también de los responsables de política laboral, de los recién graduados y de la sociedad en general. Y es que las consecuencias para la trayectoria laboral de estar en un empleo con requerimientos de cualificación inferiores a las del trabajador no deben infravalorarse, ya que la sobreeducación puede convertirse en una trampa para el desarrollo de la carrera profesional (Verhaest et al., 2015; Acosta-Ballesteros et al., 2018; Meroni y Vera-Toscano, 2017).

En un contexto de expansión universitaria y elevadas tasas de desempleo los estudiantes saben que sus características académicas y extra-académicas pueden marcar la diferencia a la hora de encontrar un empleo adecuado a sus cualificaciones. Esta idea tiene su reflejo en tres de las principales teorías que abordan las causas del desajuste al inicio de la vida laboral: la teoría del capital humano (Becker, 1994), la teoría de la señal (Spence, 1973; Stiglitz, 1975) y la teoría del desarrollo de la carrera profesional (Sicherman y Galor, 1990). La primera sostiene que el desajuste al inicio de la vida profesional se debe a la falta de experiencia laboral; la segunda sugiere que se debe a la deficiente señal sobre la productividad del joven que todavía no cuenta con experiencia ni con historial laboral; y la tercera argumenta que el desajuste es una estrategia a corto plazo (elección racional) para entrar en el mercado de trabajo y dar un primer paso hacia la promoción dentro y/o fuera de la empresa. En los tres casos está implícita la idea de que la experiencia laboral reduce la incidencia del desajuste; bien porque con la experiencia el trabajador adquiere el capital humano del que se carece al terminar los estudios; bien porque mejora la información sobre la productividad del propio trabajador (o, en la medida en la que esté relacionada con el campo de estudios, un posible ahorro en formación específica); o bien porque le proporciona mayores oportunidades de promoción dentro y/o fuera de la empresa. En una línea parecida, y dando más protagonismo a la dimensión de la oferta de trabajo que a la demanda, la literatura más reciente explora la insuficiente dotación de habilidades y competencias, así como la falta de información sobre las oportunidades que ofrece el mercado de trabajo y sus exigencias como factores explicativos del subempleo en los jóvenes. La expansión de la educación superior tiene como resultado una mayor heterogeneidad en dichas competencias entre los graduados, llegando incluso a hacer menos nítida que antes la distinción entre los empleos para trabajadores de cualificación media y alta (Scurry y Blenkinsopp, 2011).

Trabajar durante los estudios puede ser una manera de mejorar las oportunidades en el mercado de trabajo, pero también puede ser el reflejo de una necesidad económica. En España la carga financiera asociada a los estudios universitarios recae sobre el Estado, las familias y el empleo de los propios estudiantes, especialmente cuando tienen dificultades económicas o deseos de independencia financiera y/o residencial. Así se ha comprobado recientemente en España a partir de la encuesta 
ECOVIPEU 2013 (Encuesta de Condiciones de Vida y Participación de los Estudiantes Universitarios): los estudiantes trabajan cada vez con más frecuencia y quienes lo hacen tienden a provenir de familias humildes (Finkel y Barañano, 2014). En tales casos, la igualdad de oportunidades puede verse comprometida, ya que trabajar mientras se estudia reduce tanto las posibilidades de graduarse (Hovdhaugen, 2015) como las de obtener buenas notas (Triventi, 2014), sobre todo si el trabajo es intenso -Sánchez-Gelabert et al. (2017) lo advierten en egresados de universidades catalanas, Bonnal et al. (2018) en universidades francesas y Baert et al. (2018) en Flandes. Corroboran así la evidencia resumida la revisión de la literatura que aparece en Neyt et al. (2017).

En cuanto al impacto de trabajar durante los estudios en la posterior inserción laboral, la evidencia es escasa y sobre todo, dispersa. En Australia se percibe una reducción en el tiempo necesario para lograr un empleo e incluso cierta prima salarial entre quienes han trabajado durante los estudios, si bien también se advierte con preocupación que buena parte del trabajo realizado como estudiante guardaba poca relación con los estudios cursados, lo que puede tener efectos adversos en la carrera profesional (Coates, 2015). En Reino Unido se encuentran impactos semejantes de las experiencias laborales que cuentan con el apoyo de las universidades, en especial cuando además los empleadores se implican en el diseño de las prácticas (Mason et al., 2009). Por su parte, Weiss et al. (2014) analizan el efecto de diferentes tipos de experiencia laboral durante los estudios sobre tres indicadores de empleabilidad en Alemania: el tiempo de búsqueda transcurrido hasta encontrar el primer empleo, la ocupación y el salario cinco años después de graduarse. Sus resultados sugieren que ni la experiencia laboral no relacionada con el área de estudio ni las prácticas curriculares obligatorias tienen efecto en la empleabilidad; incluso podrían llegar a tener efectos negativos, de manera que solo la experiencia laboral voluntaria relacionada con el área de estudios tiene efectos positivos en la empleabilidad de los titulados.

Jackson y Collings (2018) es uno de los pocos trabajos que aborda el efecto de la experiencia laboral durante los estudios (que incluye empleo en el mercado de trabajo, prácticas y experiencias que cuentan con apoyo de las universidades WIL, work-integrated learning) sobre el desajuste educativo tras la graduación en Australia. Sus resultados sugieren que la experiencia laboral mejora el ajuste educativo de los recién graduados a medio plazo, pero no indaga en el efecto de diferentes tipos de experiencia. Con relación a las experiencias laborales con apoyo de las instituciones -esencialmente prácticas- en Mason et al. (2009) se encuentra evidencia de una mayor probabilidad de tener un empleo adecuado para estudios superiores (a graduate job) seis meses tras la graduación. Finalmente, en Sánchez-Gelabert et al. (2017) se muestra un indicador sintético de calidad del empleo cuatro años tras la graduación que captura, entre otras cuestiones, el desajuste educativo. Un análisis ANOVA (Analysis of Variance) muestra que, en comparación con los estudiantes a tiempo completo, los mejores indicadores de calidad del empleo son sistemáticamente más elevados en estudiantes que han tenido un trabajo de jornada completa relacionado con los estudios, seguidos de quienes lo habían tenido a tiempo parcial, 
mientras que el indicador de calidad es algo más bajo entre quienes habían trabajado en algo no relacionado con los estudios.

La información disponible en las encuestas Eurostudent V (2015) y ECOPIVEU (2013) indica que la incidencia del trabajo mientras se estudia en la universidad es más baja en España (46 por 100) que en otros países de nuestro entorno (en Alemania y Suiza, el 57 por 100, y en Holanda casi alcanza el 80 por 100), pero no se sitúa entre las más bajas; queda por delante de Francia e Italia, con 40 y 27 por 100, respectivamente. No obstante, señalan los autores que el porcentaje de estudiantes que trabajan en algo relacionado con sus estudios no se diferencia mucho de estos otros países (Sánchez-Gelabert et al., 2017).

El objetivo de este trabajo es estudiar el efecto que tienen diferentes tipos de experiencia laboral durante los estudios sobre la calidad del primer empleo de los jóvenes graduados en España. Concretamente exploramos el efecto de dos tipos de experiencia durante el periodo de formación: la adquirida mediante trabajos remunerados y mediante prácticas en empresas, instituciones o similares. En el primer caso diferenciamos entre la experiencia relacionada con los estudios y la no relacionada con estos, por tipo de jornada (parcial o completa) y duración del trabajo. Para el segundo caso diferenciamos entre las prácticas curriculares -que forman parte del plan de estudios- y las extracurriculares, que no están contempladas en él, aunque pueden tener reconocimiento académico.

El artículo se estructura en tres apartados, además de la introducción. En el apartado de datos y metodología se expone la base de datos utilizada en el análisis, la selección de la muestra, la definición de las variables más relevantes para el análisis y la metodología multivariante aplicada. En los dos últimos apartados presentamos los resultados y las conclusiones, respectivamente.

\section{Datos y metodología}

\subsection{Datos y selección de la muestra}

La Encuesta de Inserción Laboral de los Titulados Universitarios (EILU) es una base de datos elaborada por el Instituto Nacional de Estadística (INE) y dirigida a obtener información de los titulados en primer y segundo ciclo y los graduados en las universidades españolas durante el curso académico 2009/2010. Contiene información de cinco fuentes: el Sistema Integrado de Información Universitaria (SIIU), el Padrón, la Seguridad Social, el Servicio Público de Empleo Estatal y una encuesta. La recogida de los datos de la encuesta se hizo entre septiembre de 2014 y febrero de 2015, de manera que en el momento de su realización hubieran pasado como mínimo tres años desde que los estudiantes habían terminado sus estudios. La encuesta es representativa de los egresados universitarios en el conjunto del territorio nacional. Se selecciona una muestra aleatoria utilizando un muestreo monoetápico sin reposición y con probabilidades iguales. Dentro de cada celda definida por comunidad 
autónoma y CNED-2000 (Clasificación Nacional de Educación) se ha seleccionado una muestra aleatoria simple de titulados.

Gracias a la información procedente de las fuentes anteriormente citadas, la EILU 2014 aporta datos académicos extraídos de los registros de las universidades, como la titulación alcanzada -incluidos los estudios oficiales de posgrado-, la obtención de becas, los estudios realizados en el extranjero y la experiencia de prácticas externas gestionadas o reconocidas por las universidades. El cuestionario cuenta con preguntas sobre búsqueda del primer empleo, nivel autopercibido de competencias extra-académicas, características del primer empleo tras la graduación y del empleo en el momento de la entrevista, entre otros aspectos. Para una descripción completa de la base de datos consultar INE (2016).

A pesar de su riqueza, esta base de datos tiene dos puntos débiles que atañen a nuestros objetivos: el primero es que no se recaba información sobre la familia de origen del entrevistado, lo cual impide que podamos discernir si la experiencia laboral durante los estudios fue una estrategia para incrementar la empleabilidad futura o fruto de la necesidad económica. El segundo es que tampoco se conoce la experiencia laboral previa a los estudios universitarios, de modo que se puede estar infravalorando la experiencia de los egresados y su impacto. De ser así, nuestras estimaciones adolecerían de un sesgo por variables omitidas, más probable cuanto mayor sea la edad de los graduados universitarios y, por tanto, su experiencia potencial. Por este motivo se ha seleccionado exclusivamente a los entrevistados menores de treinta años de edad en el momento de la graduación, de modo que de una muestra inicial de 30.379 casos se retiene inicialmente al 59 por 100 de la muestra (17.934 observaciones).

Como se ha indicado antes, la EILU-2014 dispone de información muy detallada sobre el tipo de programa que desarrollaron los entrevistados. Recoge a Ingenieros superiores $(5,36$ por 100$)$ y técnicos $(10,73$ por 100$)$, licenciados $(47,17$ por 100$)$, diplomados $(22,19$ por 100$)$ y maestros $(12,79$ por 100$)$, y en este análisis no se han incluido ni a los graduados con el Plan Bolonia (1,65 por 100) ni a otras titulaciones $(0,12$ por 100$)$. Además, necesariamente se selecciona a aquellos egresados para los que se dispone de información sobre su primer empleo y se excluye a los que no han trabajado desde que se graduaron $(6,23$ por 100$)$.

La muestra así seleccionada es de 16.515 casos (que se reduce en algo más de 1.000 casos en el análisis multivariante por los missing en las diversas variables) y puede verse en el Anexo el valor medio de las variables construidas para medir el desajuste y para explicarlo. El 65,78 por 100 de la muestra son mujeres, casi el 34 por 100 por ha estudiado Ciencias Sociales y Jurídicas, el 13,81 por 100 se graduó en una universidad privada, el 38,23 por 100 cursó estudios de postgrado tras graduarse, el 42,18 por 100 necesitó menos de tres meses para encontrar su primer empleo (de hecho, parte de ellos no tuvo que buscar, al seguir trabajando en el empleo que tenían mientras estudiaban) y apenas un 6,58 por 100 inició su vida laboral como egresado en el extranjero. 


\subsection{Medidas de desajuste educativo}

En este artículo adoptamos tres medidas subjetivas de desajuste: sobreeducación, desajuste en conocimientos y habilidades y desajuste en el área de estudios. Si bien una parte no desdeñable de los entrevistados se ve afectada por más de una forma de desajuste, merece la pena considerarlas por separado pues, a diferencia de lo que podríamos esperar, los trabajadores que tienen empleos desajustados a su nivel educativo no necesariamente tienen carencias en habilidades. Para el caso de España, con datos del estudio PIAAC, Nieto y Ramos (2017) muestran que, para un mismo nivel educativo, los trabajadores sobreeducados tienen menos habilidades que los que están bien ajustados, mientras que los infraeducados tienen más. Con la misma base de datos, Mateos-Romero y Salinas-Jiménez (2017) encuentran que uno de cada tres trabajadores sobre o infraeducados están correctamente ajustados en términos de habilidades.

A continuación, detallamos las medidas de desajuste aquí analizadas, todas ellas construidas a partir de las preguntas sobre el primer empleo tras la graduación en el cuestionario de la EILU-2014:

- Sobreeducación (desajuste vertical). La respuesta a la pregunta: «¿Cuál crees que era el nivel de formación más apropiado para realizar ese trabajo?», se agrupa en cinco niveles educativos: 1$)$ doctorado o posdoctorado $(0,88$ por $100)$; 2) título universitario excepto doctorado (62,92 por 100$)$; 3 ) formación profesional de grado superior (12,71 por 100); 4) formación profesional de grado medio/bachillerato (9,33 por 100); 5) ESO, EGB o menos (14,16 por 100). Consideramos sobreeducados en su primer empleo a los entrevistados que manifiestan que su primer empleo requería de un nivel educativo inferior al título universitario (36,2 por 100 del total).

- Desajuste con los conocimientos y habilidades adquiridos en el estudio. Esta medida surge de la pregunta « ¿Se hacía uso en ese trabajo de los conocimientos y habilidades adquiridos en esa carrera?». Este indicador toma el valor uno si el entrevistado no utilizaba los conocimientos y habilidades adquiridos en la carrera $(29,77$ por 100$)$ y cero si los utilizaba.

- Desajuste con el área de estudios (desajuste horizontal). Al responder a la pregunta «¿Cuál era el área de estudio más apropiada para este trabajo?», el entrevistado puede elegir entre: 1) exclusivamente su propia área de estudio $(29,28$ por 100$) ; 2$ ) su propia área o alguna relacionada (42,99 por 100); 3) un área totalmente diferente $(11,91$ por 100$)$; y 4) ningún área en particular (15,81 por 100). Identificamos el desajuste horizontal mediante una variable dicotómica que toma el valor uno para las respuestas 3) y 4), que recoge por tanto a aquellos cuyo primer empleo no estaba relacionado con su área de estudio $(27,73$ por 100), y cero para los que contestan 1) o 2), identificando así alguna relación efectiva entre el primer empleo y el área de estudio. 


\subsection{Medidas de experiencia laboral durante los estudios}

- Experiencia adquirida mediante trabajos remunerados durante los estudios. Para identificar los diferentes tipos de experiencia hemos combinado tres preguntas de la encuesta. La primera, «¿Ha tenido algún trabajo remunerado durante la realización de los estudios?», permite saber si ha trabajado durante los estudios. A los entrevistados que contestan afirmativamente $(50,92$ por 100 del total) se les pregunta si este trabajo estaba relacionado con su formación y, finalmente, por el tipo de jornada y su duración.

El Cuadro 1 muestra el porcentaje de jóvenes que no trabajaron durante los estudios y los que sí lo hicieron, y para este último colectivo se presenta la distribución entre los que su empleo estaba relacionado con los estudios y los que no. Además, para cada uno de estos dos últimos grupos se presenta la distribución según las características del empleo (duración del contrato y tipo de jornada laboral). En el Cuadro 1 también puede consultarse la incidencia de los tres tipos de desajuste para cada uno de los casos. El 39,07 por 100 de los egresados que trabajaron durante sus estudios lo hizo en algo relacionado con ellos; casi la mitad de estos desarrollaron su trabajo durante más de tres meses, mientras que casi la mitad de quienes no trabajaron en nada relacionado con sus estudios lo hicieron de forma esporádica, durante menos de tres meses. La incidencia del desajuste es siempre más alta entre quienes trabajaron durante sus estudios que entre quienes no lo hicieron, si bien es importante el matiz que aporta la relación del empleo con los estudios: es sistemáticamente mayor el desajuste cuando el trabajo durante la carrera no guardaba relación con los estudios y menor cuando sí estaba relacionado, hasta el punto de que en ese caso son menores los niveles de desajuste en el ámbito de los conocimientos/habilidades y área de estudios que los egresados sin experiencia laboral durante los estudios. La duración de esta experiencia y el tipo de jornada guardan una relación opuesta con el desajuste según la relación del empleo con los estudios, de manera que la experiencia laboral relacionada con los estudios mejora especialmente los niveles de desajuste si se desarrollaba a jornada completa durante más de tres meses, mientras que la experiencia en trabajos no relacionados con los estudios es menos perjudicial para el desajuste de todo tipo si estos eran esporádicos. 


\section{CUADRO 1 \\ DISTRIBUCIÓN DE JÓVENES EGRESADOS E INCIDENCIA DEL DESAJUSTE \\ EN EL PRIMER EMPLEO SEGÚN EXPERIENCIA ADQUIRIDA MEDIANTE TRABAJOS REMUNERADOS DURANTE LOS ESTUDIOS}

\begin{tabular}{|c|c|c|c|c|}
\hline $\begin{array}{l}\text { Experiencia laboral durante } \\
\text { los estudios adquirida fuera del } \\
\text { entorno universitario }\end{array}$ & $\%$ & $\begin{array}{c}\text { Sobre- } \\
\text { educación }\end{array}$ & $\begin{array}{c}\text { Desajuste } \\
\text { conoci- } \\
\text { mientos y } \\
\text { habilidades }\end{array}$ & $\begin{array}{l}\text { Desajuste } \\
\text { área de } \\
\text { estudios }\end{array}$ \\
\hline $\begin{array}{l}\text { No trabajó durante los estudios } \\
\text { Sí trabajó durante los estudios } \\
\text { Características del empleo de los } \\
\text { jóvenes que trabajaron durante los } \\
\text { estudios }\end{array}$ & $\begin{array}{l}49,08 \\
50,92\end{array}$ & $\begin{array}{l}30,42 \\
41,12\end{array}$ & $\begin{array}{l}25,19 \\
33,63\end{array}$ & $\begin{array}{l}22,72 \\
31,97\end{array}$ \\
\hline $\begin{array}{l}\text { Trabajo relacionado con los estudios } \\
\text { De los cuales, }\end{array}$ & 39,07 & 32,40 & 20,03 & 17,21 \\
\hline $\begin{array}{l}\text { Esporádico durante menos } \\
\text { de } 3 \text { meses }\end{array}$ & 30,77 & 36,71 & 25,19 & 23,65 \\
\hline $\begin{array}{l}\text { A jornada parcial durante más } \\
\text { de } 3 \text { meses }\end{array}$ & 45,80 & 32,33 & 18,97 & 16,41 \\
\hline $\begin{array}{l}\text { A jornada completa durante más } \\
\text { de } 3 \text { meses }\end{array}$ & 23,43 & 27,01 & 15,33 & 10,35 \\
\hline $\begin{array}{l}\text { Trabajo NO relacionado con los } \\
\text { estudios } \\
\text { De los cuales, }\end{array}$ & 60,93 & 46,58 & 42,10 & 27,62 \\
\hline $\begin{array}{l}\text { Esporádico durante menos } \\
\text { de } 3 \text { meses }\end{array}$ & 49,74 & 38,10 & 32,66 & 31,36 \\
\hline $\begin{array}{l}\text { A jornada parcial durante más } \\
\text { de } 3 \text { meses }\end{array}$ & 38,97 & 54,40 & 50,72 & 49,76 \\
\hline $\begin{array}{l}\text { A jornada completa durante más } \\
\text { de } 3 \text { meses }\end{array}$ & 11,28 & 56,29 & 53,18 & 54,50 \\
\hline
\end{tabular}

FUENTE: Encuesta de Inserción Laboral de los Titulados Universitarios 2014 (INE).

- Prácticas en empresas, instituciones o similares que se han realizado durante el periodo de formación, normalmente conocidas como prácticas externas. Estas tienen como objetivo complementar la formación académica de los universitarios mediante experiencias laborales vinculadas a la titulación que cursan. Diferenciamos entre prácticas externas curriculares y extracurriculares. Las curriculares están integradas en el plan de estudios y para algunas titulaciones como Magisterio o Enfermería son obligatorias, mientras que para otras no lo son ${ }^{1}$. Las prácticas extracurriculares no forman parte del plan de estudios y las

${ }^{1}$ Es conveniente recordar que al estudiar egresados del curso 2009/2010 estamos analizando exclusivamente licenciados, diplomados, ingenieros y arquitectos del marco académico pre-Bolonia, en el que las prácticas externas curriculares estaban menos extendidas que en el sistema actual. 
realizan los alumnos de manera voluntaria durante el periodo en el que cursan la titulación. En ambos tipos de prácticas la universidad gestiona las ofertas de plazas, aunque en algunos casos el alumno puede presentar una propuesta de práctica extracurricular que es evaluada y, en su caso, reconocida por la universidad. Independiente de su naturaleza curricular o no curricular las prácticas tienen una duración muy variable, que va desde un mes hasta, excepcionalmente, más de un año. Distinguiremos la incidencia del desajuste de acuerdo a dicha duración junto con el tipo de práctica externa.

\section{CUADRO 2 \\ DISTRIBUCIÓN DE JÓVENES EGRESADOS E INCIDENCIA \\ DEL DESAJUSTE EN EL PRIMER EMPLEO SEGÚN TIPO DE PRÁCTICAS EN EMPRESAS, INSTITUCIONES O SIMILARES REALIZADAS DURANTE EL PERIODO DE FORMACIÓN}

\begin{tabular}{|c|c|c|c|c|}
\hline $\begin{array}{c}\text { Experiencia laboral durante los } \\
\text { estudios adquirida en el entorno } \\
\text { universitario }\end{array}$ & $\%$ & $\begin{array}{c}\text { Sobre- } \\
\text { educación }\end{array}$ & $\begin{array}{c}\text { Desajuste } \\
\text { conoci- } \\
\text { mientos y } \\
\text { habilidades }\end{array}$ & $\begin{array}{c}\text { Desajuste } \\
\text { área de } \\
\text { estudios }\end{array}$ \\
\hline \multicolumn{5}{|l|}{ Prácticas curriculares } \\
\hline No las realizó & 29,37 & 36,05 & 33,77 & 30,91 \\
\hline Sí las realizó & 70,63 & 36,26 & 28,12 & 26,41 \\
\hline \multicolumn{5}{|l|}{$\begin{array}{l}\text { Duración de las prácticas } \\
\text { curriculares }\end{array}$} \\
\hline De 1 a 3 meses & 37,90 & 42,76 & 34,06 & 31,30 \\
\hline De 4 a 6 meses & 30,79 & 39,27 & 28,83 & 28,02 \\
\hline De 7 a 9 meses & 9,93 & 30,29 & 22,48 & 21,72 \\
\hline De 10 a 12 meses & 8,48 & 22,56 & 17,16 & 16,68 \\
\hline Más de un año & 7,99 & 17,55 & 15,66 & 12,87 \\
\hline La realizó pero NS/NC la duración & 4,91 & 34,55 & 29,82 & 27,96 \\
\hline \multicolumn{5}{|l|}{ Prácticas extracurriculares } \\
\hline No las realizó & 65,13 & 36,22 & 29,49 & 27,88 \\
\hline Sí las realizó & 34,87 & 36,14 & 30,30 & 27,45 \\
\hline \multicolumn{5}{|l|}{$\begin{array}{l}\text { Duración de las prácticas } \\
\text { extracurriculares }\end{array}$} \\
\hline De 1 a 3 meses & 38,05 & 38,91 & 31,86 & 30,23 \\
\hline De 4 a 6 meses & 27,09 & 36,91 & 31,44 & 27,58 \\
\hline De 7 a 9 meses & 8,78 & 36,94 & 30,32 & 27,75 \\
\hline De 10 a 12 meses & 12,77 & 31,06 & 26,89 & 23,77 \\
\hline Más de un año & 9,33 & 28,40 & 24,44 & 19,76 \\
\hline La realizó pero NS/NC la duración & 3,99 & 37,80 & 32,68 & 29,95 \\
\hline
\end{tabular}

FUENTE: Encuesta de Inserción Laboral de los Titulados Universitarios 2014 (INE). 
El Cuadro 2 muestra la distribución de las variables construidas con esta información. El 70,63 por 100 de la muestra desarrolló prácticas curriculares y el 34,87 por 100 consiguió en algún momento prácticas extracurriculares. Las primeras tienen una duración ligeramente inferior a las segundas. Destaca la menor incidencia del desajuste en conocimientos y habilidades y en área de estudio entre los estudiantes que realizan prácticas curriculares, mientras que realizar prácticas extracurriculares no se corresponde con un menor porcentaje en los indicadores de ajuste educativo en su primer empleo tras graduarse. Entre los que realizan prácticas externas, la duración de las prácticas sí parece ser relevante tanto en las curriculares como en las extracurriculares: cuanto mayor es su duración, menor es la incidencia del desajuste en el primer empleo. Esta pauta se corrobora en los tres indicadores de desajuste y es más intensa/apreciable en las prácticas curriculares que en las extracurriculares.

\subsection{Estrategia multivariante}

Estimamos un modelo probit para cada dimensión de subempleo: a) sobreeducación, $b$ ) infrautilización de los conocimientos y habilidades adquiridos en los estudios, y $c$ ) desajuste con el área de los estudios. Explicaremos la probabilidad de estar desajustado mediante las variables de experiencia laboral durante los estudios y un conjunto de variables de control: características personales, tipo de universidad, otras características académicas, características del primer empleo y características de la búsqueda del primer empleo.

La ecuación [1] presenta la especificación del modelo:

$$
D_{k}^{*}=\beta_{1} \operatorname{Exp}_{i}^{S}+\beta_{2} X_{i}^{P}+\beta_{3} X_{i}^{J}+\varepsilon_{i}
$$

$D_{k}^{*}$ es un vector de variables latentes que representan la probabilidad de estar desajustados en una serie de $k$ formas de desajuste (1, sobreeducación, 2, infrautilización de conocimientos y habilidades y 3 , desajuste con el área de los estudios). El primer conjunto de variables explicativas, $\operatorname{Exp}^{\mathrm{s}}$, se refiere a la experiencia laboral durante los estudios. $X^{P}$ es un vector de variables explicativas que reflejan características personales (género) y académicas y de habilidades o competencias, como el campo de estudio (que combina rama de conocimiento y tipo de programa académico), el tipo de universidad, haber estudiado en el extranjero antes de la graduación, haber obtenido becas de excelencia o de colaboración como estudiante universitario de diplomatura o licenciatura, nivel de inglés y habilidades informáticas. El conjunto de variables de control se completa con un vector $X^{J}$ que recoge las características del primer empleo: situación profesional y tipo de contrato en los asalariados, jornada parcial frente a tiempo completo y haber conseguido el primer empleo en el extranjero. También se controla por el tiempo transcurrido desde la graduación hasta el comienzo del primer trabajo y las estrategias de búsqueda utilizadas por el entrevistado para lograr el primer empleo, que pueden influir en el riesgo de desajuste 
experimentado en dicho puesto de trabajo (véase Albert y Davia, 2018). Finalmente, $\varepsilon_{i}$ es un término de error i.i.d.

Al estudiar exclusivamente a los graduados con experiencia laboral podríamos pensar en la existencia de un sesgo de selección, aunque dado el escaso porcentaje de entrevistados que no han logrado ningún empleo tras la graduación creemos que este sesgo no es relevante. Sí cabe en cambio reconocer un posible sesgo por endogeneidad de las variables explicativas principales, que se daría si el efecto de las experiencias laborales durante los estudios capturase características inobservadas que están relacionadas con el potencial de empleabilidad (adecuada) y la propensión a realizar actividades laborales relacionadas con los estudios durante la carrera. No se aborda aquí la corrección de este posible sesgo debido a la falta de información para diseñar instrumentos adecuados, como por ejemplo características familiares, habilidades y/o competencias².

\section{Resultados y discusión}

El Cuadro 3 muestra los efectos marginales para los modelos probit que estiman la probabilidad de los tres tipos de desajuste inicial de los jóvenes graduados. El Cuadro combina los resultados de dos especificaciones complementarias, formuladas por razones de multicolinealidad: en una se recoge la incidencia de prácticas curriculares y extracurriculares y en la otra se identifica la duración de dichas prácticas. Por razones de espacio, en el Cuadro 3 no se muestran los efectos marginales correspondientes a las variables explicativas referidas a las características del primer empleo (tipo de jornada, tipo de contrato y situación profesional), los métodos de búsqueda del primer empleo y el tiempo transcurrido desde que finalizó la carrera hasta que empezó a trabajar. El lector que lo desee puede solicitar esta información a los autores ${ }^{3}$.

Los primeros resultados muestran que realizar un trabajo remunerado durante los estudios tiene un efecto diferente en el riesgo de desajuste dependiendo de si este trabajo estaba o no relacionado con los estudios: si lo estaba, se reduce el riesgo de subempleo; en caso contrario, el riesgo de desajuste es mayor. Estos efectos se confirman para las tres medidas de desajuste utilizadas (vertical, de conocimientos

\footnotetext{
${ }^{2}$ Las autoras agradecen a un evaluador anónimo la invitación a reflexionar sobre esta cuestión de la endogeneidad de la experiencia laboral previa a la graduación por heterogeneidad inobservada, que sin duda constituye una posible línea de mejora metodológica en futuras explotaciones de la EILU-2014.

${ }^{3}$ Del mismo modo, no se muestran los resultados de las pruebas de robustez realizadas. Se ha comprobado con ellas si los efectos marginales de las variables que registran experiencia laboral durante los estudios se ven afectados por la inclusión de controles por características académicas, nivel de competencias y métodos de búsqueda que podrían ser endógenos a dichas experiencias, así como a las características del primer empleo que también podrían verse afectadas por la propia experiencia laboral o la adquisición de prácticas. Están disponibles para el lector interesado. Las autoras agradecen a un evaluador anónimo la propuesta de realización de dichos contrastes de robustez, dado el riesgo de que algunas de las variables antes mencionadas sean un «mal control» en la terminología de ANGRIST y PISCHKE (2008), al estar potencialmente explicadas por las variables explicativas de interés en este trabajo.
} 


\section{CUADRO 3}

\section{EFECTOS MARGINALES DE MODELOS PROBIT CON DIFERENTES MEDIDAS DE SUBEMPLEO COMO VARIABLE DEPENDIENTE}

\begin{tabular}{|c|c|c|c|c|}
\hline & & $\begin{array}{c}\text { Sobre- } \\
\text { educación }\end{array}$ & $\begin{array}{c}\text { Desajuste } \\
\text { conocimientos } \\
\text { y habilidades }\end{array}$ & $\begin{array}{l}\text { Desajuste } \\
\text { área de } \\
\text { estudios }\end{array}$ \\
\hline $\begin{array}{c}\text { Experiencia } \\
\text { adquirida mediante } \\
\text { trabajo remunerado } \\
\text { durante los estudios } \\
\text { (Ref. No trabajó durante } \\
\text { los estudios) }\end{array}$ & $\begin{array}{l}\text { Trabajo relacionado con } \\
\text { los estudios } \\
\text { Esporádico durante } \\
\text { menos de } 3 \text { meses } \\
\text { Jornada parcial } \\
\text { durante más de } 3 \text { meses } \\
\text { Jornada completa } \\
\text { durante más de } 3 \text { meses } \\
\text { Trabajo NO relacionado } \\
\text { con los estudios } \\
\text { Esporádico durante } \\
\text { menos de } 3 \text { meses } \\
\text { Jornada parcial } \\
\text { durante más de } 3 \text { meses } \\
\text { Jornada completa } \\
\text { durante más de } 3 \text { meses }\end{array}$ & $\begin{array}{c}0,0309 * * \\
(0,0145) \\
-0,0759 * * * \\
(0,0141) \\
-0,0740 * * * \\
(0,0194) \\
\\
0,0642 * * * \\
(0,0101) \\
0,0926 * * * \\
(0,0125) \\
0,1473 * * * \\
(0,0202)\end{array}$ & $\begin{array}{c}-0,0239 \\
(0,0147) \\
-0,1009 * * * \\
(0,0141) \\
-0,1041 * * * \\
(0,0203) \\
\\
0,0563 * * * \\
(0,0098) \\
0,1474 * * * \\
(0,0119) \\
0,1995 * * * \\
(0,0192)\end{array}$ & $\begin{array}{c}-0,0127 \\
(0,0138) \\
-0,1151 * * * \\
(0,0137) \\
-0,1502 * * * \\
(0,0204) \\
\\
0,0690 * * * \\
(0,0093) \\
0,1397 * * * \\
(0,0112) \\
0,2083 * * * \\
(0,0181)\end{array}$ \\
\hline $\begin{array}{c}\text { Prácticas } \\
\text { (Ref. No realizó estas } \\
\text { prácticas) }\end{array}$ & $\begin{array}{l}\text { Prácticas curriculares } \\
\text { Prácticas extracurriculares }\end{array}$ & $\begin{array}{c}-0,0070 \\
(0,0088) \\
0,0159 * * \\
(0,0075) \\
\end{array}$ & $\begin{array}{c}-0,0245^{* * *} * \\
(0,0085) \\
0,0153 * * \\
(0,0073) \\
\end{array}$ & $\begin{array}{c}-0,0086 \\
(0,0081) \\
0,0103 \\
(0,0070) \\
\end{array}$ \\
\hline $\begin{array}{c}\text { Duración de las prácticas } \\
\text { curriculares } \\
\text { (Ref. No realizó estas } \\
\text { prácticas) }\end{array}$ & $\begin{array}{l}\text { De } 1 \text { a } 3 \text { meses } \\
\text { De } 4 \text { a } 6 \text { meses } \\
\text { De } 7 \text { a } 9 \text { meses } \\
\text { De } 10 \text { a } 12 \text { meses } \\
\text { Más de un año } \\
\text { Realizó prácticas pero } \\
\text { NS/NC su duración }\end{array}$ & $\begin{array}{c}0,0012 \\
(0,0101) \\
0,0023 \\
(0,0108) \\
-0,0174 \\
(0,0157) \\
-0,0412 * * \\
(0,0177) \\
-0,0397 * * \\
(0,0195) \\
-0,0331 \\
(0,0223) \\
\end{array}$ & $\begin{array}{c}-0,0129 \\
(0,0098) \\
-0,0317 * * * \\
(0,0106) \\
-0,0436 * * * \\
(0,0157) \\
-0,0551 * * * \\
(0,0178) \\
-0,0192 \\
(0,0190) \\
-0,0002 \\
(0,0215) \\
\end{array}$ & $\begin{array}{c}-0,0060 \\
(0,0094) \\
-0,0035 \\
(0,0100) \\
-0,0171 \\
(0,0149) \\
-0,0302 * \\
(0,0171) \\
-0,0299 \\
(0,0187) \\
0,0082 \\
(0,0206) \\
\end{array}$ \\
\hline $\begin{array}{c}\text { Duración de las prácticas } \\
\text { extracurriculares } \\
\text { (Ref. No realizó estas } \\
\text { prácticas) }\end{array}$ & $\begin{array}{l}\text { De } 1 \text { a } 3 \text { meses } \\
\text { De } 4 \text { a } 6 \text { meses } \\
\text { De } 7 \text { a } 9 \text { meses } \\
\text { De } 10 \text { a } 12 \text { meses } \\
\text { Más de un año } \\
\text { Realizó prácticas pero } \\
\text { NS/NC su duración }\end{array}$ & $\begin{array}{c}0,0159 \\
(0,0105) \\
0,0057 \\
(0,0122) \\
0,0384 * \\
(0,0200) \\
0,0253 \\
(0,0175) \\
-0,0043 \\
(0,0204) \\
0,0558^{*} \\
(0,0310)\end{array}$ & $\begin{array}{c}0,0093 \\
(0,0103) \\
0,0153 \\
(0,0119) \\
0,0250 \\
(0,0196) \\
0,0254 \\
(0,0172) \\
0,0014 \\
(0,0204) \\
0,0283 \\
(0,0306)\end{array}$ & $\begin{array}{c}0,0154 \\
(0,0097) \\
-0,0088 \\
(0,0115) \\
0,0178 \\
(0,0189) \\
0,0313^{*} \\
(0,0164) \\
-0,0071 \\
(0,0200) \\
0,0285 \\
(0,0297)\end{array}$ \\
\hline
\end{tabular}

FUENTE: Encuesta de Inserción Laboral de los Titulados Universitarios 2014 (INE). Errores estándar entre paréntesis; ${ }^{* *} p<0,01,{ }^{* *} p<0,05,{ }^{*} p<0,1$. Variables de control adicionales (disponibles previa solicitud): $a$ ) tipo de jornada, tipo de contrato, situación profesional y primer empleo en el extranjero; $b$ ) métodos de búsqueda del primer empleo; y c) tiempo transcurrido desde que finalizó la carrera hasta que empezó a trabajar. 
CUADRO 3 (Cont.)

EFECTOS MARGINALES DE MODELOS PROBIT CON DIFERENTES MEDIDAS DE SUBEMPLEO COMO VARIABLE DEPENDIENTE

\begin{tabular}{|c|c|c|c|c|}
\hline & & $\begin{array}{l}\text { Sobre- } \\
\text { educación }\end{array}$ & $\begin{array}{c}\text { Desajuste } \\
\text { conocimientos } \\
\text { y habilidades }\end{array}$ & $\begin{array}{l}\text { Desajuste área } \\
\text { de estudios }\end{array}$ \\
\hline $\begin{array}{c}\text { Género } \\
\text { (Ref. Varones) }\end{array}$ & Mujeres & $\begin{array}{l}-0,0009 \\
(0,0080)\end{array}$ & $\begin{array}{c}0,0093 \\
(0,0078)\end{array}$ & $\begin{array}{c}0,0022 \\
(0,0074)\end{array}$ \\
\hline $\begin{array}{c}\text { Campo de estudio } \\
\text { (Ref. Licenciado en Artes } \\
\text { y Humanidades) }\end{array}$ & $\begin{array}{l}\text { Ingeniero o arquitecto } \\
\text { superior } \\
\text { Ingeniero o arquitecto } \\
\text { técnico } \\
\text { Licenciado en Ciencias } \\
\text { Licenciado en Ciencias } \\
\text { Sociales y Jurídicas } \\
\text { Licenciado en Ciencias } \\
\text { de la Salud } \\
\text { Diplomado en Ciencias } \\
\text { Sociales y Jurídicas } \\
\text { Maestro } \\
\text { Diplomado en Ciencias } \\
\text { de la Salud }\end{array}$ & $\begin{array}{c}-0,0817 * * * \\
(0,0199) \\
0,0008 \\
(0,0162) \\
-0,0477 * * * \\
(0,0167) \\
0,0276 * * \\
(0,0140) \\
-0,2611 * * * \\
(0,0242) \\
0,1239 * * * \\
(0,0164) \\
0,0237 \\
(0,0165) \\
-0,2693 * * * \\
(0,0178)\end{array}$ & $\begin{array}{c}-0,0797 * * * \\
(0,0194) \\
-0,0119 \\
(0,0158) \\
-0,0387 * * \\
(0,0161) \\
-0,0044 \\
(0,0136) \\
-0,2742 * * * \\
(0,0240) \\
0,0495 * * * \\
(0,0159) \\
-0,0577 * * * \\
(0,0161) \\
-0,2614 * * * \\
(0,0179)\end{array}$ & $\begin{array}{c}-0,1384 * * * \\
(0,0190) \\
-0,0608 * * * \\
(0,0149) \\
-0,0895 * * * \\
(0,0152) \\
-0,0479 * * * \\
(0,0128) \\
-0,2803 * * * \\
(0,0230) \\
-0,0216 \\
(0,0149) \\
-0,1108 * * * \\
(0,0151) \\
-0,2904 * * * \\
(0,0167)\end{array}$ \\
\hline $\begin{array}{c}\text { Tipo de Universidad } \\
\text { (Ref. Privada) }\end{array}$ & Universidad Pública & $\begin{array}{c}0,0279 * * * \\
(0,0106) \\
\end{array}$ & $\begin{array}{c}0,0361 * * * \\
(0,0106) \\
\end{array}$ & $\begin{array}{c}0,0216 * * \\
(0,0101)\end{array}$ \\
\hline $\begin{array}{c}\text { Estudios en el extranjero } \\
\text { (Ref. No ha estudiado en el } \\
\text { extranjero) }\end{array}$ & $\begin{array}{l}\text { Ha estudiado de } 1 \text { a } 6 \text { meses } \\
\text { en el extranjero } \\
\text { Ha estudiado más de } \\
6 \text { meses en el extranjero }\end{array}$ & $\begin{array}{c}-0,0407 * * \\
(0,0168) \\
-0,0438 * * * \\
(0,0159)\end{array}$ & $\begin{array}{l}-0,0053 \\
(0,0164) \\
-0,0021 \\
(0,0153)\end{array}$ & $\begin{array}{c}-0,0207 \\
(0,0158) \\
-0,0257 * \\
(0,0149)\end{array}$ \\
\hline $\begin{array}{c}\text { Estudios de posgrado } \\
\text { (Ref. No cursó un posgrado) }\end{array}$ & $\begin{array}{l}\text { Cursó un posgrado } \\
\text { en España } \\
\text { Cursó un posgrado en el } \\
\text { extranjero }\end{array}$ & $\begin{array}{c}-0,0251 * * * \\
(0,0079) \\
-0,0561 * * \\
(0,0248) \\
\end{array}$ & $\begin{array}{c}-0,0187 * * \\
(0,0078) \\
0,0020 \\
(0,0232)\end{array}$ & $\begin{array}{c}-0,0157 * * \\
(0,0074) \\
0,0063 \\
(0,0221) \\
\end{array}$ \\
\hline $\begin{array}{c}\text { Becas } \\
\text { (Ref. No disfrutó de esa } \\
\text { beca) }\end{array}$ & $\begin{array}{l}\text { Beca de excelencia o de co- } \\
\text { laboración en la Universidad } \\
\text { Beca para realizar estudios } \\
\text { fuera de España o a hacer } \\
\text { prácticas externas }\end{array}$ & $\begin{array}{c}-0,0367 * * * \\
(0,0140) \\
0,0178 \\
(0,0142)\end{array}$ & $\begin{array}{l}-0,0105 \\
(0,0136) \\
-0,0072 \\
(0,0139)\end{array}$ & $\begin{array}{c}0,0111 \\
(0,0129) \\
0,0020 \\
(0,0134)\end{array}$ \\
\hline $\begin{array}{c}\text { Nivel de conocimiento } \\
\text { de inglés } \\
\text { (Ref. No habla inglés) }\end{array}$ & $\begin{array}{l}\text { Habla inglés NO muy bien } \\
\text { Habla inglés MUY bien }\end{array}$ & $\begin{array}{c}0,0029 \\
(0,0120) \\
-0,0635 * * * \\
(0,0126)\end{array}$ & $\begin{array}{c}-0,0159 \\
(0,0118) \\
-0,0478 * * * \\
(0,0124)\end{array}$ & $\begin{array}{c}-0,0065 \\
(0,0112) \\
-0,0489 * * * \\
(0,0118)\end{array}$ \\
\hline
\end{tabular}

FUENTE: Encuesta de Inserción Laboral de los Titulados Universitarios 2014 (INE). Errores estándar entre paréntesis; $* * * p<0,01$, ** $\mathrm{p}<0,05, * p<0,1$; Variables de control adicionales (disponibles previa solicitud): a) tipo de jornada, tipo de contrato y situación profesional y primer empleo en el extranjero; $b$ ) métodos de búsqueda del primer empleo; y c) tiempo transcurrido desde que finalizó la carrera hasta que empezó a trabajar. 


\section{CUADRO 3 (Cont.)}

\section{EFECTOS MARGINALES DE MODELOS PROBIT CON DIFERENTES MEDIDAS DE SUBEMPLEO COMO VARIABLE DEPENDIENTE}

\begin{tabular}{|c|c|c|c|c|}
\hline & & $\begin{array}{c}\text { Sobre- } \\
\text { educación }\end{array}$ & $\begin{array}{c}\text { Desajuste } \\
\text { conocimientos } \\
\text { y habilidades }\end{array}$ & $\begin{array}{c}\text { Desajuste área } \\
\text { de estudios }\end{array}$ \\
\hline \multirow[t]{2}{*}{$\begin{array}{l}\text { Capacidad para } \\
\text { usar el ordenador } \\
\text { (Ref. Inferior a } \\
\text { la mediana de su } \\
\text { titulación) }\end{array}$} & $\begin{array}{l}\text { Igual que la mediana } \\
\text { de su titulación } \\
\text { Por encima de la } \\
\text { mediana de su titu- } \\
\text { lación }\end{array}$ & $\begin{array}{c}-0,0246 * * * \\
(0,0095) \\
-0,0318 * * \\
(0,0133)\end{array}$ & $\begin{array}{c}-0,0113 \\
(0,0094) \\
-0,0189 \\
(0,0130)\end{array}$ & $\begin{array}{c}-0,0092 \\
(0,0088) \\
0,0082 \\
(0,0123)\end{array}$ \\
\hline & $\begin{array}{l}\text { Pseudo R2 } \\
\text { Chi-cuadrado } \\
\text { Log-verosimilitud }\end{array}$ & $\begin{array}{c}0,19 \\
3.655 \\
-7.750\end{array}$ & $\begin{array}{c}0,17 \\
2.908 \\
-7283\end{array}$ & $\begin{array}{c}0,20 \\
3.469 \\
-6.861\end{array}$ \\
\hline \multicolumn{2}{|c|}{ Número de observaciones } & 14.668 & 14.394 & 14.623 \\
\hline
\end{tabular}

FUENTE: Encuesta de Inserción Laboral de los Titulados Universitarios 2014 (INE). Errores estándar entre paréntesis; $* * * p<0,01, * * p<0,05, * p<0,1$; Variables de control adicionales (disponibles previa solicitud): a) tipo de jornada, tipo de contrato y situación profesional y primer empleo en el extranjero; $b$ ) métodos de búsqueda del primer empleo; y c) tiempo transcurrido desde que finalizó la carrera hasta que empezó a trabajar.

y habilidades y horizontal). En el caso de trabajos relacionados con los estudios, encontramos una diferencia significativa para experiencias esporádicas, inferiores a tres meses, ya que aumenta la probabilidad de estar sobreeducado (pero no la de otras formas de desajuste). Sin embargo, con una duración de más de tres meses, la probabilidad de desajuste en conocimientos y habilidades disminuye en diez puntos porcentuales, independientemente de la jornada. El riesgo de desajuste en la rama de estudios se ve reducido en 11,5 puntos porcentuales si se trabajó más de tres meses a tiempo parcial y 15 si se trabajó a tiempo completo.

Las prácticas curriculares están correlacionadas con un menor riesgo de desajuste solo en el caso de los conocimientos y habilidades y no muestran ninguna influencia en la sobreeducación ni en el desajuste relacionado con el área de estudios. En las estimaciones en las que se han sustituido la incidencia de prácticas curriculares y extracurriculares por su duración encontramos un menor riesgo de sobreeducación solo para las prácticas curriculares de diez meses o más de duración. En cambio, para el desajuste en conocimientos y habilidades no se observa ningún efecto en las prácticas de duración inferior a tres meses o superior al año ${ }^{4}$.

Las prácticas extracurriculares están relacionadas con una mayor probabilidad de estar sobreeducado (1,59 p.p.) y de tener un primer empleo en el que los cono-

${ }^{4}$ En las pruebas de robustez comentadas en la nota al pie anterior se ha comprobado que, en ausencia de control por las características del primer empleo, las prácticas (tanto curriculares como no curriculares) de duración superior al año, sí reducen el riesgo de los tres tipos de desajuste aquí analizados. Esto indica que existe correlación entre las características del empleo actual y las prácticas de larga duración y que a su vez incrementa el riesgo de desajustes de todo tipo, contrarrestando el efecto inicialmente positivo de la realización de prácticas de larga duración. 
cimientos y las habilidades no son las apropiadas (1,53 p.p.). Aunque significativo, el impacto es tan pequeño que desaparece cuando incorporamos esta información en el modelo a través de las variables que capturan la duración de dichas prácticas extracurriculares.

Nuestros resultados están en la línea de los obtenidos por Jackson y Collings (2018) y Weiss et al. (2014), y matizan los postulados de las principales teorías que explican el subempleo (capital humano, señalización y desarrollo de la carrera profesional), en la medida en la que muestran que no toda experiencia laboral durante los estudios es apropiada para reducir el riesgo de subempleo tras la graduación.

Los resultados anteriormente comentados se observan en presencia de los controles que capturan características tanto de los egresados como de sus primeros empleos tras graduarse. En el Cuadro 3 se muestran los efectos marginales del género (que no resulta ser significativo) y de variables que recogen características académicas y de habilidades o competencias de los graduados (los resultados para el resto de las variables de control están a disposición del lector interesado). Su presencia es relevante en el modelo y es también interesante señalar que en los contrastes de robustez realizados su ausencia no altera la significatividad de las variables relacionadas con experiencia laboral previa a la graduación.

En primer lugar, destacan las muy pronunciadas diferencias por campos de conocimiento: en comparación con los licenciados de Artes y Humanidades es muy notable el menor desajuste de los licenciados y diplomados de Ciencias de la Salud, seguidos de ingenieros y arquitectos superiores, mientras que los graduados en Ciencias Sociales y Jurídicas tienen mejores resultados en desajuste horizontal pero peores en desajuste vertical y en el relacionado con los conocimientos y habilidades. Los egresados de las universidades privadas tienen menores riesgos de desajuste de todo tipo. El haber cursado parte de los estudios en el extranjero solo reduce el riesgo de sobreeducación. También lo hace el haber cursado un postgrado en el extranjero, mientras que haberlo cursado en España mejora el ajuste en todas las dimensiones analizadas.

La obtención de becas tan solo reduce el riesgo de sobreeducación. Además del desempeño académico, las habilidades extracurriculares pueden ser importantes: un buen dominio (autodeclarado) de inglés mejora los tres tipos de desajuste incluso en presencia de estudios cursados en el extranjero antes y después de la graduación en 2009/2010. En cambio las habilidades informáticas - autovaloración de la capacidad para usar el ordenador - tan solo están negativamente relacionadas con el riesgo de sobreeducación.

\section{Conclusiones}

En este trabajo hemos estudiado si la experiencia laboral y las prácticas externas durante los estudios reducen el riesgo de subempleo en el primer empleo tras finalizar la carrera universitaria. Para ello hemos utilizado la Encuesta de Inserción 
Laboral de los Titulados Universitarios 2014, que nos permite identificar tres tipos de desajuste entre cualificación y empleo (sobreeducación, en conocimientos o habilidades y por rama de estudios). La conclusión fundamental del trabajo es que no toda experiencia laboral durante los estudios reduce la probabilidad de desajuste en el primer empleo. Es necesario que esté relacionada con los estudios y que no sea esporádica. Este resultado se muestra tanto en la experiencia que aportan tanto los trabajos remunerados relacionados con los estudios como las prácticas curriculares, que al estar reconocidas en el plan de estudios tienen relación con los contenidos y habilidades adquiridos en la titulación cursada. El resto de experiencias laborales durante los estudios no guardan relación o incluso mantienen una relación positiva con el riesgo de subempleo, también en el caso de las prácticas extracurriculares que, en principio, deberían tener relación con los estudios.

En cuanto a las prácticas organizadas por las universidades, también se perciben matices en nuestros resultados que llevan a la necesidad de diseñarlas adecuadamente. Así, en las curriculares se aprecia que solo a partir de una duración mínima de tres meses contribuyen a la adquisición de competencias o señales que reducen el riesgo de subempleo posterior, pero si tienen una duración superior a los nueve meses también podrían señalizar alguna carencia en competencias o habilidades que contraponga la ventaja inicial de la mera participación en ellas. Por eso es esencial repensar el diseño de las prácticas, sin descartar propuestas de introducirlas en diversos momentos durante los estudios y no necesariamente al final (en un modelo de sandwich course en la terminología anglosajona), y fomentar que sean obligatorias en los planes de estudios, para lo cual será imprescindible que el diseño de la titulación tenga un compromiso con la empleabilidad (Silva et al., 2016).

Tanto las instituciones de educación superior como los responsables de políticas laborales y los propios egresados universitarios pueden plantear estrategias para reducir su grado de desajuste con el mercado laboral. Las instituciones universitarias adoptan medidas relacionadas con los planes de estudio, los métodos de enseñanza y/o las prácticas. Los responsables de las políticas laborales suelen recurrir a medidas relacionadas con las bonificaciones en la contratación de los jóvenes o las condiciones de los contratos en prácticas para hacer más atractiva la contratación de jóvenes cualificados. Por su parte, los jóvenes se plantean adquirir una mayor o mejor capacitación para el trabajo, normalmente a través de la formación y la experiencia laboral, incluso aunque esto implique trasladar su lugar de residencia. Todas estas actuaciones son costosas (en tiempo y dinero) y no siempre tienen suficientes garantías de éxito, por lo que es aconsejable que estén fundamentadas en la evidencia empírica. En este trabajo hemos mostrado que las inversiones que todos los agentes implicados hagan para facilitar la experiencia laboral temprana de los universitarios deben estar muy bien dirigidas a proporcionar a los jóvenes experiencias laborales relacionadas con su formación y deben contar con una mínima duración que garantice la adquisición de competencias y habilidades que les diferencien de los graduados que no busquen estas experiencias. 


\section{Referencias bibliográficas}

[1] ACOSTA-BALLESTEROS, J.; ROSAL, M. DEL P. O. y RODRÍGUEZ-RODRÍGUEZ, O. M. (2018). «Overeducation of young workers in Spain: How much does the first job matter?». Social Indicators Research, 138 (1), 109-139.

[2] ALBERT, C. y DAVIA, M. A. (2018). «Job search strategies and underemployment in recent graduates first jobs in Spain». Revista de Economía Aplicada (en prensa).

[3] ANGRIST, J. D. y PISCHKE, J. S. (2008). Mostly Harmless Econometrics: An Empiricist's Companion. Princeton University Press.

[4] BAERT S.; MARX, I.; BRECHT, N.; VAN BELLE, E. y VAN CASTEREN, J. (2017). «Student employment and academic performance: an empirical exploration of the primary orientation theory». Applied Economics Letters, 25 (8), 547-552.

[5] BECKER, G. S. (1994). Human capital: A theoretical and empirical analysis with special reference to education (3rd revised edition). Chicago: University of Chicago Press.

[6] BONNAL, L.; FAVARD, P. y KADY MARIE-DANIELLE SORHO-BODY (2018). «Does Working to Pay for Higher Education Really Harm French Academic Results?». International Journal of Manpower (en prensa).

[7] COATES, H. (2015). «Working on a dream: Educational returns from off-campus paid work». Journal of Education and Work, 28 (1), 66-82.

[8] FINKEL, L. y BARAÑANO, M. (2014). «La dedicación al estudio y al trabajo de los estudiantes universitarios en España». Revista de la Asociación de Sociología de la Educación, 7, 82-103.

[9] HOVDHAUGEN, E. (2015). «Working while studying: The impact of term-time employment on dropout rates». Journal of Education and Work, 28 (6), 631-651.

[10] INE (2016). Encuesta de Inserción Laboral de los Titulados Universitarios EILU-2014. Metodología. Recuperado de https://goo.gl/17D9Qd.

[11] JACKSON, D. y COLLINGS, D. (2018). «The influence of Work-Integrated Learning and paid work during studies on graduate employment and underemployment». Higher Education, 73 (3), 403-425,

[12] LINDBERG, M. E. (2007). «At the Frontier of Graduate Surveys'». Higher Education, $53(5), 623-644$.

[13] DACRE POOL, L. y SEWELL, P. (2007). «The key to employability: Developing a practical model of graduate employability». Education + Training, 49 (4), 277-289.

[14] MASON, G.; WILLIAMS, G. y CRANMER, S. (2009). «Employability skills initiatives in higher education: What effects do they have on graduate labour market outcomes?». Education Economics, 17 (1), 1-30.

[15] MATEOS-ROMERO, L. y SALINAS-JIMÉNEZ, M. DEL M. (2017). «Skills heterogeneity among graduate workers: Real and apparent overeducation in the Spanish labor market». Social Indicators Research, 132 (3), 1247-1264.

[16] MERONI, E. C. y VERA-TOSCANO, E. (2017). «The persistence of overeducation among recent graduates». Labour Economics, 48 (Supplement C), 120-143.

[17] NEYT, B.; OMEY, E.; VERHAEST, D. y BAERT, S. (2017). «Does Student Work Really Affect Educational Outcomes? A Review of the Literature». IZA DP No. 11023.

[18] NIETO, S. y RAMOS, R. (2017). «Overeducation, skills and wage penalty: Evidence for Spain using PIAAC data». Social Indicators Research, 134 (1), 219-236. 
[19] SÁNCHEZ-GELABERT, A.; FIGUEROA, M. y ELÍAS, M. (2017). «Working whilst studying in higher education: The impact of the economic crisis on academic and labour market success». European Journal of Education, 52 (2), 232-245.

[20] SCURRY, T. y BLENKINSOPP, J. (2011). «Under-employment among recent graduates: A review of the literature». Personnel Review, 40 (5), 643-659.

[21] SICHERMAN, N. y GALOR, O. (1990). «A theory of career mobility». Journal of Political Economy, 98 (1), 169-192.

[22] SILVA, P.; LOPES, B.; COSTA, M.; SEABRA, D.; MELO, A. I.; BRITO, E. y DIAS, G. P. (2016). «Stairway to employment? Internships in higher education». Higher Education, 72 (6), 703-721.

[23] SPENCE, M. (1973). «Job market signaling». The Quarterly Journal of Economics, 87 (3), 355.

[24] STIGLITZ, J. E. (1975). «The theory of "Screening" education, and the distribution of income». American Economic Review, 65 (3), 283-300.

[25] TRIVENTI, M. (2014). «Does working during higher education affect students' academic progression?». Economics of Education Review, 41, 1-13.

[26] VERHAEST, D.; SCHATTEMAN, T. y VAN TRIER, W. (2015). «Overeducation in the early career of secondary education graduates: An analysis using sequence techniques». Young, 23 (4), 336-356.

[27] WEISS, F.; KLEIN, M. y GRAUENHORST, T. (2014). «The effects of work experience during higher education on labour market entry: learning by doing or an entry ticket?». Work, Employment and Society, 28 (5), 788-807. 


\section{ANEXO}

TABLA A

VALORES MEDIOS DE LAS VARIABLES UTILIZADAS EN EL ANÁLISIS

\begin{tabular}{|c|c|c|}
\hline Variable & & $\%$ \\
\hline Medidas de subempleo & $\begin{array}{l}\text { Sobreeducación } \\
\text { Desajuste (infrautilización) en conocimien- } \\
\text { tos y habilidades } \\
\text { Desajuste en área de estudios }\end{array}$ & $\begin{array}{l}36,20 \\
29,77 \\
27,73\end{array}$ \\
\hline \multicolumn{3}{|l|}{ Variables independientes } \\
\hline \multicolumn{3}{|l|}{ Características personales } \\
\hline Género & $\begin{array}{l}\text { Mujeres } \\
\text { Varones }\end{array}$ & $\begin{array}{l}65,78 \\
34,22\end{array}$ \\
\hline \multicolumn{3}{|c|}{ Características académicas y habilidades } \\
\hline Rama de conocimiento & $\begin{array}{l}\text { Ingeniero o arquitecto superior } \\
\text { Ingeniero o arquitecto técnico } \\
\text { Licenciado en Artes y Humanidades } \\
\text { Licenciado en Ciencias } \\
\text { Licenciado en Ciencias Sociales y Jurídicas } \\
\text { Licenciado en Ciencias de la salud } \\
\text { Diplomado en Ciencias Sociales y Jurídicas } \\
\text { Maestro } \\
\text { Diplomado en Ciencias de la Salud }\end{array}$ & $\begin{array}{r}5,86 \\
11,09 \\
9,19 \\
8,60 \\
23,46 \\
6,47 \\
10,52 \\
12,96 \\
11,84\end{array}$ \\
\hline Tipo de universidad & $\begin{array}{l}\text { Universidad pública } \\
\text { Otra universidad }\end{array}$ & $\begin{array}{l}86,19 \\
13,81\end{array}$ \\
\hline Estudios en el extranjero & $\begin{array}{l}\text { No ha estudiado en el extranjero } \\
\text { Ha estudiado de } 1 \text { a } 6 \text { meses en el extranjero } \\
\text { Ha estudiado más de } 6 \text { meses en el extranjero }\end{array}$ & $\begin{array}{l}0,83 \\
0,07 \\
0,10\end{array}$ \\
\hline Estudios de posgrado & $\begin{array}{l}\text { No cursó un posgrado } \\
\text { Cursó un posgrado en España } \\
\text { Cursó un posgrado en el extranjero } \\
\end{array}$ & $\begin{array}{r}61,77 \\
36,12 \\
2,11 \\
\end{array}$ \\
\hline Becas disfrutadas & $\begin{array}{l}\text { Beca de excelencia o de colaboración en la } \\
\text { universidad } \\
\text { Beca para realizar estudios fuera de España } \\
\text { o a hacer prácticas externas }\end{array}$ & $\begin{array}{r}7,70 \\
14,04\end{array}$ \\
\hline \multirow{3}{*}{ Nivel de conocimiento de inglés } & No habla inglés & 15,25 \\
\hline & Habla inglés NO muy bien & 45,54 \\
\hline & Habla inglés MUY bien & 39,21 \\
\hline Capacidad para usar el ordenador & $\begin{array}{l}\text { Por debajo de la mediana de su titulación } \\
\text { Igual que la mediana de su titulación } \\
\text { Por encima de la mediana de su titulación }\end{array}$ & $\begin{array}{r}72,92 \\
19,06 \\
8,03\end{array}$ \\
\hline
\end{tabular}

FUENTE: Encuesta de Inserción Laboral de los Titulados Universitarios 2014 (INE). 
TABLA A (Cont.)

VALORES MEDIOS DE LAS VARIABLES UTILIZADAS EN EL ANÁLISIS

\begin{tabular}{|c|c|c|}
\hline Variable & & $\%$ \\
\hline \multicolumn{3}{|l|}{ Características del primer empleo } \\
\hline Jornada laboral & $\begin{array}{l}\text { Jornada a tiempo completo } \\
\text { Jornada a tiempo parcial }\end{array}$ & $\begin{array}{l}38,04 \\
61,96\end{array}$ \\
\hline Situación profesional & $\begin{array}{l}\text { En prácticas, formación o becario } \\
\text { Asalariado con contrato permanente } \\
\text { Asalariado con contrato temporal } \\
\text { Empresario o trabajador independiente } \\
\text { Ayuda en la empresa o negocio familiar }\end{array}$ & $\begin{array}{r}25,55 \\
16,55 \\
52,20 \\
4,44 \\
1,27\end{array}$ \\
\hline Búsqueda del primer empleo & $\begin{array}{l}\text { A través de anuncios en el periódico, Inter- } \\
\text { net,... } \\
\text { A través de servicios de empleo públicos } \\
\text { o de los servicios de empleo de la univer- } \\
\text { sidad } \\
\text { A través de empresas de trabajo temporal } \\
\text { Contactó con el empleador por iniciativa } \\
\text { propia o utilizó contactos personales (fa- } \\
\text { milia, amigos) } \\
\text { El empleador se puso en contacto con la } \\
\text { persona } \\
\text { Continuó con las prácticas en empresas/ } \\
\text { instituciones que realizó durante la carrera } \\
\text { Preparó unas oposiciones } \\
\text { Montó su propio negocio } \\
\text { De otra forma }\end{array}$ & $\begin{array}{r}34,26 \\
23,06 \\
\\
10,64 \\
39,42 \\
\\
14,46 \\
8,79 \\
10,0 \\
3,49 \\
14,57\end{array}$ \\
\hline $\begin{array}{l}\text { Tiempo trabajando desde la obtención } \\
\text { del título }\end{array}$ & $\begin{array}{l}\text { Continuó al menos } 6 \text { meses más en el } \\
\text { trabajo que tenía mientras estudiaba } \\
\text { Menos de tres meses } \\
\text { De } 3 \text { a } 6 \text { meses } \\
\text { De } 6 \text { meses a } 1 \text { año } \\
\text { De } 1 \text { año a año y medio } \\
\text { De } 1 \text { año y medio a } 2 \text { años } \\
2 \text { años o más }\end{array}$ & $\begin{array}{r}15,82 \\
26,36 \\
12,85 \\
15,02 \\
10,42 \\
6,36 \\
13,16\end{array}$ \\
\hline \multirow{2}{*}{$\begin{array}{l}\text { País en el que trabajaba en el primer } \\
\text { empleo }\end{array}$} & En el extranjero & 6,58 \\
\hline & En España & 93,42 \\
\hline \multicolumn{2}{|l|}{ Número de observaciones } & 16.515 \\
\hline
\end{tabular}

FUENTE: Encuesta de Inserción Laboral de los Titulados Universitarios 2014 (INE). 